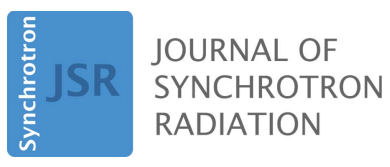

ISSN 1600-5775

Received 27 December 2020

Accepted 28 January 2021

Edited by K. Kvashnina, ESRF - The European Synchrotron, France

Keywords: APXPS; operando; in situ; synchrotron; catalysis; IR; beamline.

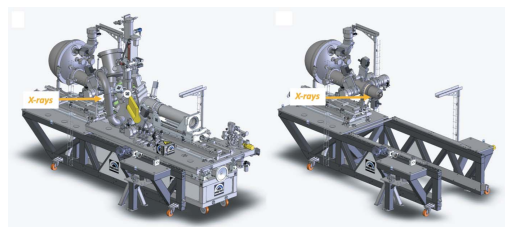

OPEN ๑ ACCESS

\title{
HIPPIE: a new platform for ambient-pressure X-ray photoelectron spectroscopy at the MAX IV Laboratory
}

\author{
Suyun Zhu, ${ }^{a}$ Mattia Scardamaglia, ${ }^{a}$ Jan Kundsen, ${ }^{\mathrm{a}, \mathrm{b}}$ Rami Sankari, ${ }^{\mathrm{a}, \mathrm{c}}$ \\ Hamed Tarawneh, ${ }^{a}$ Robert Temperton, ${ }^{\mathrm{a}}$ Louisa Pickworth, ${ }^{\mathrm{a}}$ Filippo Cavalca, \\ Chunlei Wang, ${ }^{\mathrm{d}}$ Héloïse Tissot, ${ }^{\mathrm{d}}$ Jonas Weissenrieder, ${ }^{\mathrm{d}}$ Benjamin Hagman, \\ Johan Gustafson, ${ }^{\mathrm{b}}$ Sarp Kaya, ${ }^{\mathrm{e}}$ Fredrik Lindgren, ${ }^{\mathrm{f}}$ Ida Källquist, ${ }^{\mathrm{f}}$ Julia Maibach, ${ }^{\mathrm{g}}$ \\ Maria Hahlin, ${ }^{\text {f,h }}$ Virginia Boix, ${ }^{\text {b }}$ Tamires Gallo, ${ }^{\text {b }}$ Foqia Rehman, ${ }^{\text {b }}$ Giulio D'Acunto, ${ }^{\text {b }}$ \\ Joachim Schnadt ${ }^{\mathrm{a}, \mathrm{b}}$ and Andrey Shavorskiy ${ }^{\mathrm{a} *}$
}

\begin{abstract}
'MAX IV Laboratory, Lund University, Box 118, 22100 Lund, Sweden, 'bivision of Synchrotron Radiation Research, Department of Physics, Lund University, Box 118, 22100 Lund, Sweden, ${ }^{\mathrm{c} D e p a r t m e n t ~ o f ~ P h y s i c s, ~ T a m p e r e ~ U n i v e r s i t y ~ o f ~}$ Technology, PO Box 692, FIN-33101 Tampere, Finland, 'dMaterial Physics, School of Engineering Sciences, KTH Royal Institute of Technology, 10044 Stockholm, Sweden, ${ }^{\mathbf{e}}$ Department of Chemistry, Koc University, Istanbul 34450, Turkey, ${ }^{\mathbf{f}}$ Department of Physics and Astronomy, Division of Molecular and Condensed Matter Physics, Uppsala University, 751

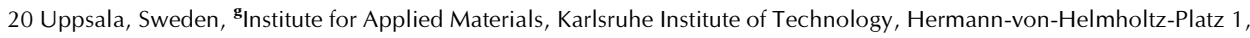
76344 Eggenstein-Leopoldshafen, Germany, and hepartment of Chemistry - Ångström Laboratory, Uppsala University, Box 538, 75121 Uppsala, Sweden. *Correspondence e-mail: andrey.shavorskiy@maxiv.lu.se
\end{abstract}

HIPPIE is a soft X-ray beamline on the $3 \mathrm{GeV}$ electron storage ring of the MAX IV Laboratory, equipped with a novel ambient-pressure X-ray photoelectron spectroscopy (APXPS) instrument. The endstation is dedicated to performing in situ and operando X-ray photoelectron spectroscopy experiments in the presence of a controlled gaseous atmosphere at pressures up to $30 \mathrm{mbar}$ $[1 \mathrm{mbar}=100 \mathrm{~Pa}]$ as well as under ultra-high-vacuum conditions. The photon energy range is 250 to $2200 \mathrm{eV}$ in planar polarization and with photon fluxes $>10^{12}$ photons s$^{-1}$ (500 $\mathrm{mA}$ ring current) at a resolving power of greater than 10000 and up to a maximum of 32000 . The endstation currently provides two sample environments: a catalysis cell and an electrochemical/liquid cell. The former allows APXPS measurements of solid samples in the presence of a gaseous atmosphere (with a mixture of up to eight gases and a vapour of a liquid) and simultaneous analysis of the inlet/outlet gas composition by online mass spectrometry. The latter is a more versatile setup primarily designed for APXPS at the solid-liquid (dip-and-pull setup) or liquid-gas (liquid microjet) interfaces under full electrochemical control, and it can also be used as an open port for ad hoc-designed non-standard APXPS experiments with different sample environments. The catalysis cell can be further equipped with an IR reflection-absorption spectrometer, allowing for simultaneous APXPS and IR spectroscopy of the samples. The endstation is set up to easily accommodate further sample environments.

\section{Introduction}

Ambient-pressure X-ray photoelectron spectroscopy (APXPS) is a powerful technique for studying the chemical composition of the interfaces between solids, liquids and gases. The method has increased in popularity in recent years, and many experimental systems have been installed both in home laboratories, making use of X-ray anodes, and at synchrotron radiation facilities (Starr et al., 2013; Arble et al., 2018; Schnadt et al., 2020). Currently almost all synchrotron light sources either have or are planning to have an instrument capable of measuring X-ray photoelectron spectroscopy (XPS) at mbar 
pressures $[1 \mathrm{mbar}=100 \mathrm{~Pa}]$. The majority of such instruments employ a back-filling scheme for creating ambient-pressure (AP) conditions in the analysis chamber. Recently, new developments have also demonstrated the high potential of an approach based on an exchangeable AP cell design for experiments in non-standard or highly demanding environments (Grass et al., 2010; Velasco-Vélez et al., 2016; Held et al., 2020).

At the former MAX-lab (which has evolved into the current MAX IV Laboratory) a new cell-in-cell approach was pioneered (Schnadt et al., 2012) as a natural development of the very early schemes of APXPS instrumentation (Siegbahn \& Siegbahn, 1973; Joyner \& Roberts, 1979; Joyner et al., 1979; Boronin et al., 1988). In this concept, which was developed simultaneously for X-ray anode-based instruments, the advantages of back-filling and exchangeable cell design are combined to allow quick switching between AP and ultra-high-vacuum (UHV) conditions without compromising sample cleanness. This is made possible by placing an AP cell inside the UHV vessel separated from the main analysis volume by a valve. The cell can then be moved by means of a motor into the analysis volume and 'docked' onto the front of the analyser in just a few minutes. In this setup an AP created inside the docked cell does not drastically compromise the vacuum in the analysis chamber, and a quick restoration of UHV conditions is possible after removal of the cell.

The first cell-in-cell approach was realized at the SPECIES beamline at MAX-lab, which is now installed on the $1.5 \mathrm{GeV}$ storage ring of the MAX IV Laboratory (Schnadt et al., 2012; Urpelainen et al., 2017; Kokkonen et al., 2021). SPECIES is a beamline that is optimized for the ultraviolet and soft X-ray range with photon energies from around $30 \mathrm{eV}$ up to $c a$ $1500 \mathrm{eV}$, which is ideal for the study of the valence band and the $K$-edge spectra of low- $Z$ elements. In contrast, HIPPIE was designed to give access to the upper end of the soft X-ray range with a high and rather constant photon flux up to $2000 \mathrm{eV}$ and additional access to the $\mathrm{P} K$ edges at a more limited flux. At the same time, a design criterion for HIPPIE was that $\mathrm{C} K$-edge X-ray absorption spectroscopy (XAS) should be possible, which required a minimum energy of around $250 \mathrm{eV}$.

HIPPIE serves a large number of different user communities, with most users coming from the surface science and catalysis domains. In order to satisfy the very different needs of the user communities, which also include e.g. energy generation and storage, electrochemistry, corrosion, oxide and semiconductor thin film growth, liquids, geo- and biochemistry and photochemistry, a highly flexible design was chosen for the instrument, which allows quick exchange between various sample environments. The communities depending on the flow type rather than the batch type of gaseous sample environments benefit from a complex, fully automatic gas dosing system with online gas analysis hardware.

Below we describe the HIPPIE beamline in more detail. We address the design goals, characteristics and performance, and give a few examples of scientific problems solved using the capabilities of the beamline.

\section{Design goals and technical details}

The following design goals were formulated for the HIPPIE beamline:

(i) To allow APXPS and soft X-ray XAS in the range between 250 and $2200 \mathrm{eV}$ at a high flux $\left(10^{13}\right.$ photons s$\left.^{-1}\right)$.

(ii) To allow APXPS at pressures up to 30 mbar with recording times of swept spectra on the minute timescale.

(iii) To allow fast acquisition of ambient-pressure X-ray photoelectron (APXP) spectra with frame rates in fixed mode of up to $120 \mathrm{~Hz}$.

(iv) To allow fully automatic gas dosing of multiple gases as well as an online analysis of gas mixtures simultaneous with XPS (also at high sampling frequency).

(v) To allow quick and easy switching between UHV and AP conditions without compromising sample cleanness.

(vi) To allow a variety of different sample environments by means of different AP cells.

The energy range demand was met by installing HIPPIE on the $3 \mathrm{GeV}$ storage ring of MAX IV. Its energy range is 250 to $2200 \mathrm{eV}$, and the photon flux is above $10^{12} \mathrm{~s}^{-1}$ (at $500 \mathrm{~mA}$ ring current) at a resolving power greater than 10000 between 250 and $2000 \mathrm{eV}$. Hence, the $K$-edge spectra of the important low$Z$ elements $\mathrm{C}, \mathrm{O}, \mathrm{N}$ and $\mathrm{F}$ are accessible, but also the $K$ edges of $\mathrm{Na}, \mathrm{Mg}$ and $\mathrm{Al}$. Excellent conditions exist for measurement of the $L$ edges of the $3 d$ transition metal elements and the important semiconductor elements $\mathrm{Ge}$ and As. The possibility of tuning the kinetic energy across a wide range implies that depth profiling for multiple photoemission levels from all elements of the periodic table is possible. Higher kinetic energy values imply an increase in the electron inelastic mean free path (IMFP) and the accessibility of the solid-liquid interfaces and solid-gas interfaces at higher pressures.

HIPPIE has two branches that use the same source and monochromator; however, at the time of writing only one branch is in operation. The other branch is assembled up to the monochromator exit slit, and recently we received funding to finish the remaining part by 2024. The branch in operation is dedicated to APXPS on interfaces between solids, liquids and gases; the pressure range is from $1 \times 10^{-9}$ up to 30 mbar.

\subsection{Beamline}

2.1.1. Source. The source of the HIPPIE beamline is an APPLE-II-type elliptically polarizing undulator (EPU). Full polarization control is achieved from a design with four arrays of permanent magnets, two of which can be shifted longitudinally to create horizontal and vertical magnetic fields (Sasaki et al., 1993). A period length of $53 \mathrm{~mm}$ was chosen to satisfy the requirement of full polarization control at a minimum energy of $250 \mathrm{eV}$, which corresponds to a minimum undulator gap of $11 \mathrm{~mm}$. This dimension was driven by the size of the vacuum pipe in the storage ring. The undulator has 70 full periods and a total length of $3.9398 \mathrm{~m}$. The design is based on glued magnet pairs, a concept developed at the MAX IV Laboratory for magnet holders with wedges for both transverse planes (Wallén et al., 2014). The HIPPIE EPU was built and characterized in-house at the MAX IV magnetic 
Table 1

Beamline details.

\begin{tabular}{ll}
\hline Beamline name & HIPPIE \\
Source type & EPU53 \\
Mirrors & Au coated \\
Monochromator & cPGM \\
Energy range $(\mathrm{keV})$ & $0.25-2.2$ \\
Wavelength range $(\AA)$ & $50-5.5$ \\
Beam size $(\mu \mathrm{m})$ & $c a 25 \times 60$ \\
Flux $($ photons s & $\left.>10^{12}\right)$ \\
\hline
\end{tabular}

measurement laboratory. The overall dimension of a single magnet block is $30 \mathrm{~mm} \times 30 \mathrm{~mm} \times 13.25 \mathrm{~mm}$. The magnetic material is $\mathrm{NdFeB}$ with a magnetic remanence of $B_{\mathrm{r}}=1.28 \mathrm{~T}$ for the vertically magnetized block and $B_{\mathrm{r}}=1.25 \mathrm{~T}$ for the longitudinally magnetized block. At the moment the HIPPIE EPU is only used in planar mode due to the highest user demand. Other polarization modes (inclined and elliptical) are awaiting commissioning, in particular energy calibration.

2.1.2. Optical design. The layout of the optical components of the HIPPIE beamline is shown in Fig. 1, and the general details of the beamline are summarized in Table 1. The beamline design is based on a plane-grating monochromator illuminated by collimated light (cPGM), a design developed at BESSY (Follath et al., 1998). The first optical component is a toroidal mirror (M1) located $24 \mathrm{~m}$ after the light source. It is designed to collimate the beam vertically and focus the beam horizontally onto the exit slit, $15 \mathrm{~m}$ further downstream. The monochromator is manufactured by Toyama and contains a plane mirror (M2) and a plane grating (PG1) with blazed profile and 1200 lines $\mathrm{mm}^{-1}$ density. The dispersed radiation from the monochromator is focused vertically onto the exit slit by the cylindrical mirror (M3). The refocusing for the APXPS branch is accomplished by a single toroidal mirror (M4). The focusing is astigmatic by design: the actual vertical focus is $25 \mathrm{~mm}$ further downstream than that of the horizontal focus, which is co-located with the sample position. The astigmatism reduces the sensitivity of the vertical beam size at the sample plane with respect to the exit slit height adjustment, which controls the energy bandwidth of the incoming radiation - this kind of focusing solution was realized and successfully tested at the SPECIES beamline (Urpelainen et al., 2017). Although easy manipulation of the photon beam location at the sample is often connected to two mirror systems in a Kirkpatrick-
Baez configuration (Kirkpatrick \& Baez, 1948), the same can be achieved with a single mirror: here the beam spot can be moved horizontally and vertically by adjusting the pitch and roll angles of the refocusing mirror, respectively. It should be noted that, due to large deviation in the meridional (long) radius of the present $\mathrm{M} 1$, the horizontal focus does not meet the sample plane and the photon beam at the sample is defocused also in the horizontal direction. The first and second mirrors (M1 and M2) are internally water cooled, whereas the PG is side cooled by water-cooled copper blocks. The focusing mirror M3 is cooled through a copper brace. The refocusing mirror, M4, receives so little heat that no cooling is necessary.

A novel mirror chamber design is used for all mirrors outside the monochromator tank, i.e. mirrors M1, M3 and M4. This design aims to keep the weight of all components very low in order to push up the fundamental vibration frequencies, which improve stability of the beam considerably. In the design the mirror is rigidly connected to the surrounding vacuum vessel. The movement of the mirror is accomplished by moving the entire chamber by means of five motors (Agåker et al., 2020). The vacuum vessel is mounted onto a granite slab which effectively brings the stability of the MAX IV experimental hall floor right below the mirror chamber. The mirror chambers do not have direct vacuum pumping; the pumping is instead accomplished via a separate pumping unit mounted on the beamline adjacent to the mirror chamber. In this way, the weight of the actual mirror chamber is reduced. The pumping unit contains an ion pump and - for M3 and M4 - a single-axis manipulator with a selection of diagnostic tools: an AXUV100G photodiode, YAG crystal and a gold mesh for drain current measurements. The X-ray beam can be shaped by four independently moving blades, each at the entrances to the monochromator tank, M3 and M4. In addition, the beam can also be shaped in the beamline's front-end by watercooled masks. These masks are used primarily for selection of the central part of the undulator cone and for decreasing the heat load on the beamline components.

2.1.3. Beamline performance. The photon flux at the beamline was measured using a photodiode and corrected for the photodiode's quantum efficiency (ITW, AXUV 100G, Opto Diode, https://optodiode.com/photodiodes-axuvdetectors.html). The photodiode was mounted on a manipulator upstream of the M4 mirror. The flux was measured at

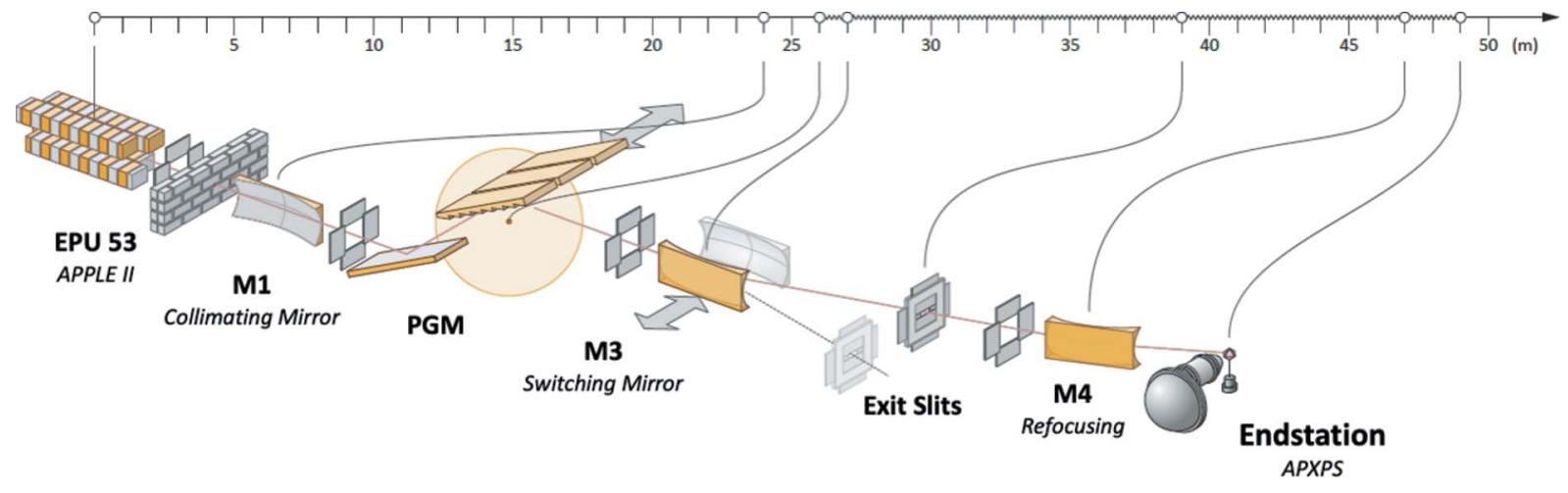

Figure 1

Optical layout of the HIPPIE beamline. 


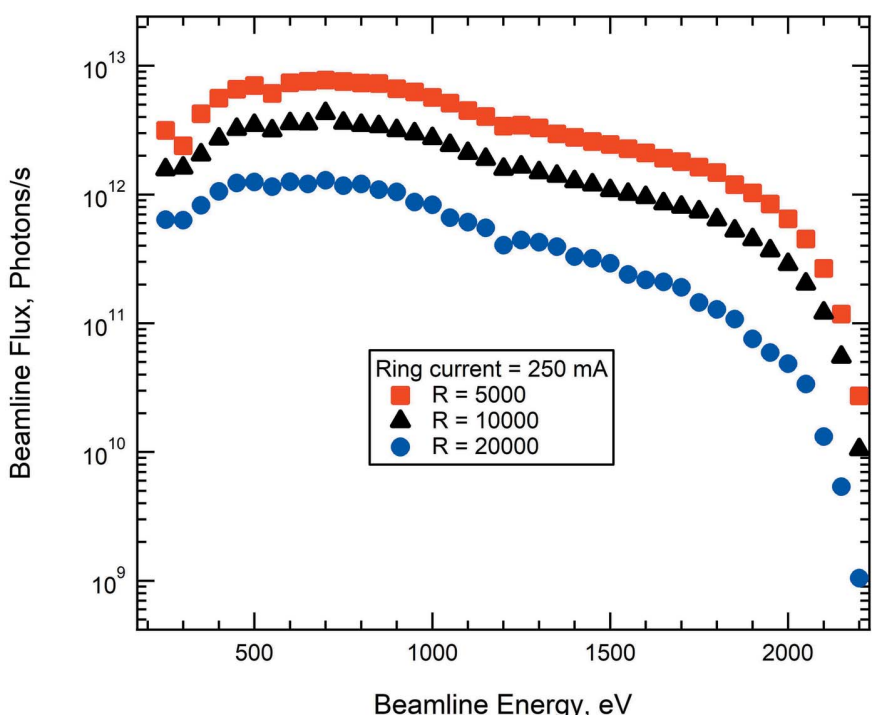

Figure 2

Beamline flux in the energy range from 250 to $2200 \mathrm{eV}$, measured with a ring current of $250 \mathrm{~mA}$ and three different resolving powers.

$250 \mathrm{~mA}$ ring current, which is half of the designed value of the $3 \mathrm{GeV}$ ring of MAX IV, with the undulator in horizontal linear polarization mode. Fig. 2 shows beamline flux from 250 to $2200 \mathrm{eV}$ with three different resolving powers; the flux is

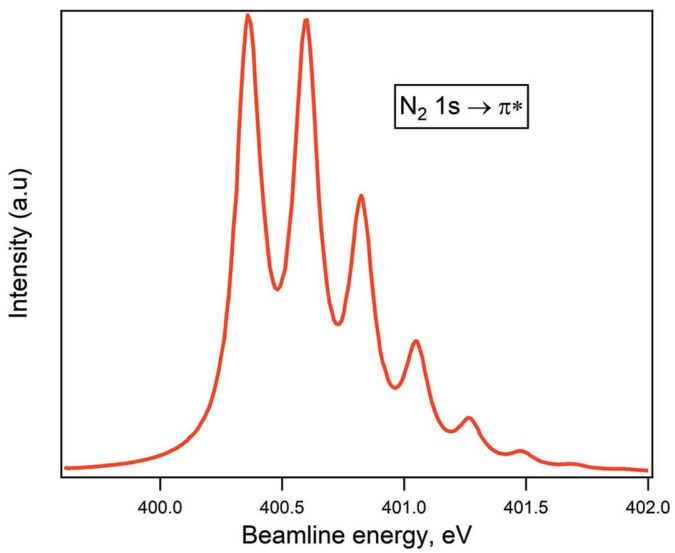

(a)

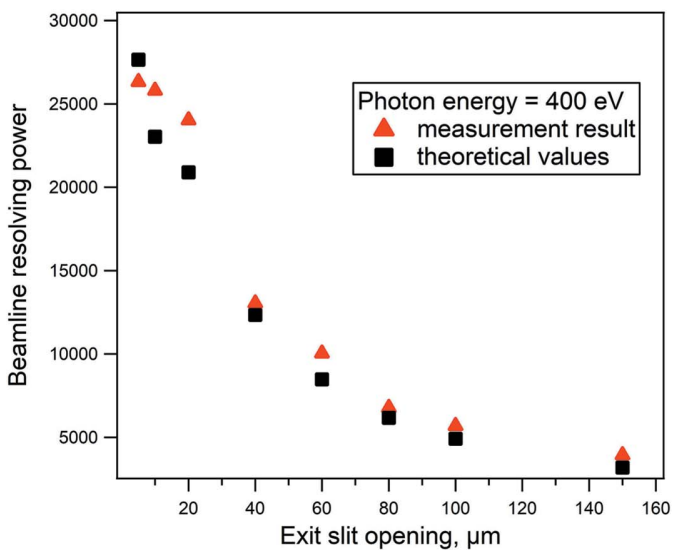

(c) higher than $1 \times 10^{12}$ photons $^{-1}$ up to a photon energy of $1600 \mathrm{eV}(2000 \mathrm{eV})$ with resolving power 10000 and $250 \mathrm{~mA}$ $(500 \mathrm{~mA})$ ring current.

The resolving power was estimated from the ion yield spectra of $\mathrm{N}_{2}$ and $\mathrm{Ne}$ gases. The measurements were conducted in a gas cell downstream of the exit slit, using a gas pressure of around $1 \times 10^{-2}$ mbar. The monochromator was operated using $c_{\mathrm{ff}}=\cos (\beta) / \cos (\alpha)=2.25$, where $\alpha$ and $\beta$ are the entrance and exit angles of the beam onto the grating, respectively. It should be noted that this $c_{\mathrm{ff}}$ value is standard for user operation mode at the beamline, and the resolving measurement presented below will thus reflect actual resolutions for users, while higher energy resolution is expected for other $c_{\mathrm{ff}}$ values. Fig. 3(a) shows the $\mathrm{N} K$-edge ion yield spectrum recorded with a $5 \mu \mathrm{m}$ exit slit opening. The beamline contribution to the line width is $c a 16 \mathrm{meV}$, which gives a resolving power of 25800 . We arrived at this result by fitting the spectrum using a Voigt profile with a Lorentzian width of $120.0 \mathrm{meV}$, a typical value found in the literature for the $\mathrm{N} 1 \mathrm{~s}$ lifetime width (Feifel et al., 2004; Kato et al., 2007a). The photon energy resolution is then deduced from the Gaussian broadening, and it is determined as an average Gaussian width of the four most intense vibrational peaks. Fig. 3(b) shows an ion yield spectrum of the $\mathrm{Ne} K$-edge Rydberg series recorded with a $5 \mu \mathrm{m}$ exit silt opening. We find a resolving power of

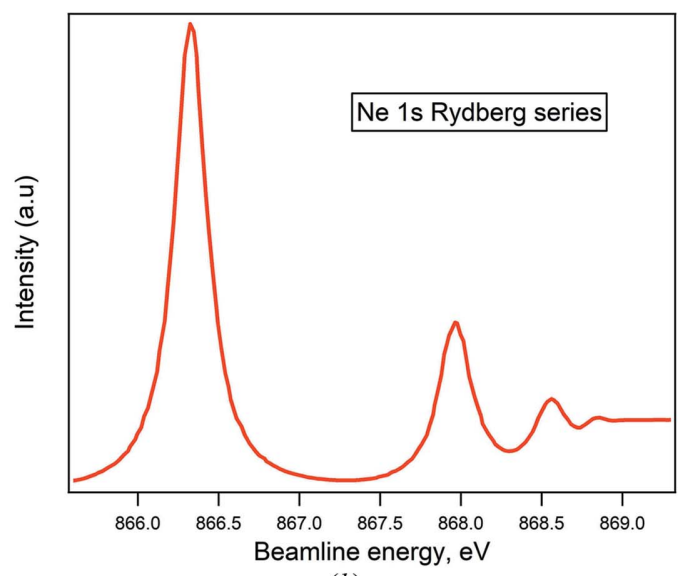

(b)

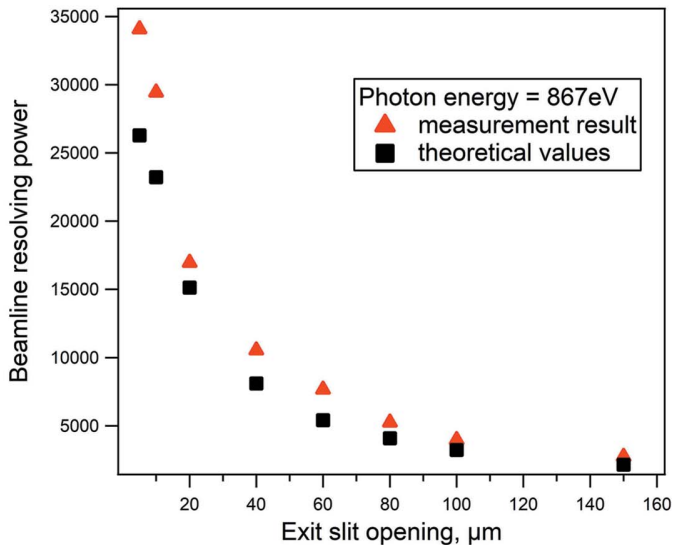

(d)

Figure 3

(a) $\mathrm{N}_{2}$ and (b) Ne $K$-edge ion yield spectra. (c) Resolving power of the beamline at $400 \mathrm{eV}$. (d) Resolving power of the beamline at $867 \mathrm{eV}$. 
32000 from the Gaussian width of the first peak of the series of ca $27 \mathrm{meV}$. In the curve fit we applied a Voigt profile with a Lorentzian width of $250 \mathrm{meV}$ (Kato et al., 2007b).

Figs. 3(c) and 3(d) compare the measured resolving power with the theoretical resolving power calculated through raytracing of the beamline. The measured resolving powers were derived from $\mathrm{N}_{2}$ and $\mathrm{Ne}$ ion yield spectra, respectively, and the ray-tracing was calculated with $R A Y$-UI developed at Helmholtz Zentrum Berlin (Baumgärtel et al., 2016). The raytracing incorporated the measured optical metrology data for the installed optical components and the same beamline settings as used in the resolving power measurement. The correspondence between the measured and theoretical values is overall good, in particular since the extraction of a Gaussian component much narrower than the Lorentzian component from a Voigt profile is difficult and seldom gives unambiguous results. It is clear, though, that the measured resolving powers indicate a beamline performance comparable with or slightly beyond the values expected from the ray-tracing.

The spot size at the sample plane was measured using a sharp edge of platinum foil. This edge was raster-scanned at the sample plane, and the drain current was used to measure the spot profile. The spot size at the sample was estimated from an evaluation of the displacement needed for the drain current intensity to change from $20 \%$ to $80 \%$. Fig. 4 shows an example measured at $400 \mathrm{eV}$ photon energy and a $10 \mu \mathrm{m}$ exit slit opening. The results for the horizontal and vertical beam sizes are ca $100 \mu \mathrm{m}$ and $25 \mu \mathrm{m}$, respectively. Considering the $35^{\circ}$ incident angle between the photon beam and the sample surface, the beam size at the sample position in the horizontal direction is $c a 60 \mu \mathrm{m}$. Both values match very well the results of the ray-tracing simulations performed including the measured figure errors of the optics.

With spherical or cylindrical optical components, small deviations in the mirror parameters from the design values can be compensated for by adjusting the incidence angle a small amount and fine-tuning the entrance and exit arms of the optical components. With this in mind, the foreseen freedom in the placement of the optical components drove the criteria set for optics procurement. However, as mentioned above, the meridional radius of the first mirror was larger, by $15 \%$, with respect to the specification $(1216580 \mathrm{~mm}$ versus $1057821.9 \mathrm{~mm}$ ), and it was obvious that this cannot be compensated for. At first glance the applicability of this mirror looks very bad: the horizontal beam size at the sample plane becomes twice as large as designed. There are, however, positive aspects in that, too. Namely, the fact that the horizontal focus is no longer at the sample plane indicates that the horizontal beam size is largely dictated by the divergence of the photon beam. As the electron beam in the MAX IV $3 \mathrm{GeV}$ ring has extremely low emittance, and the undulators are fairly long, the photon beam emitted by the source has very low divergence. The increase in horizontal beam size at the sample plane, although large taken relatively, is not large in absolute terms: the beam size is still measured in tens of micrometres.

It is interesting to see that even here, with a diffractionlimited storage ring, the beam properties along the beamline
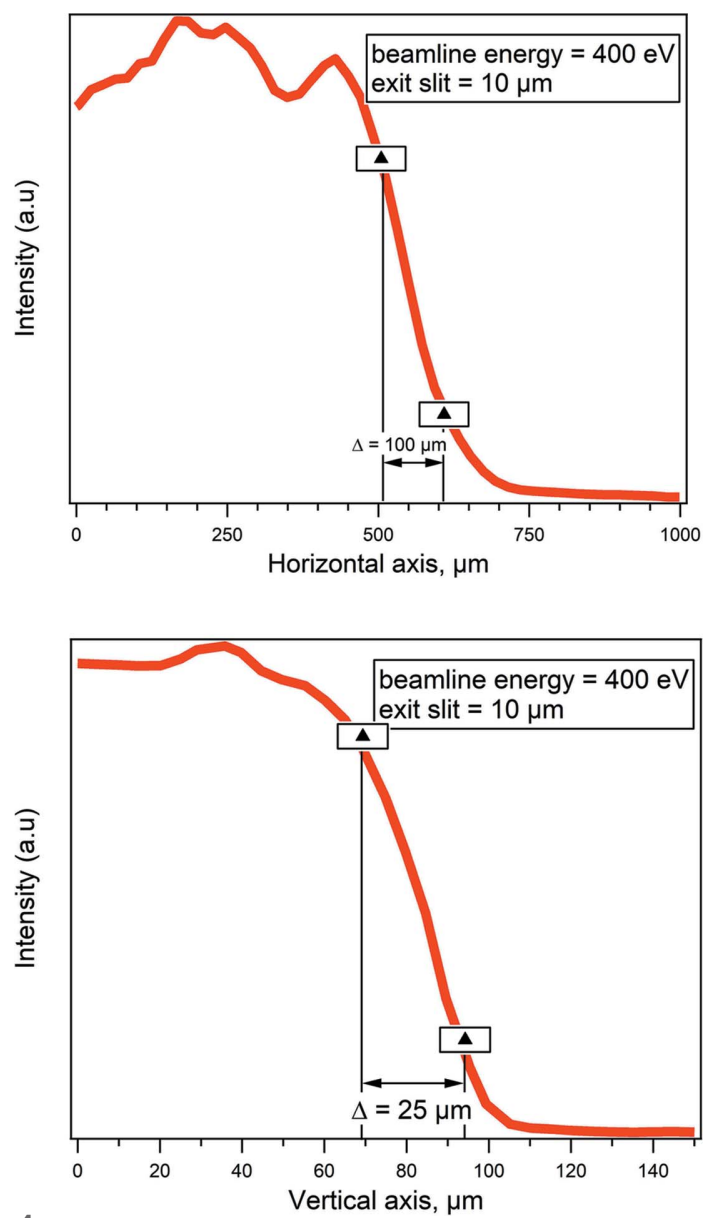

Figure 4

Beamline spot size at the sample surface. The beamline energy was $400 \mathrm{eV}$ and the exit slit set to $10 \mu \mathrm{m}$ in vertical size, the $Y$ axis in the figure is drain current from a sharp platinum foil edge, spot size was estimated from an evaluation of the displacement needed for the drain current intensity to change from $20 \%$ to $80 \%$, horizontal and vertical beam sizes in the figure are $100 \mu \mathrm{m}$ and $25 \mu \mathrm{m}$, respectively.

are further limited by diffraction. The beamline is currently operated with a reduced front-end aperture $(1.7 \mathrm{~mm} \times$ $1.9 \mathrm{~mm}$ ) that diffracts the beam and disturbs collimation of M1 vertically. The smaller aperture results in the grating being only partly illuminated, and thus affecting the achievable resolution by the diffraction limit, which in the case of gratings is simply the number of illuminated grooves. Finally, if a very small exit slit opening is used, the vertical beam profile starts to show a typical diffraction pattern at the sample plane, which is intentionally out of focus.

\subsection{APXPS endstation}

2.2.1. General design and vacuum system. The APXPS endstation was designed and produced by PREVAC sp. z.o.o. (https://www.prevac.eu/). The endstation is designed to allow for different sample environment solutions using both the cell-in-cell and exchangeable cell concepts. When switching between the two different concepts, the beamline entrance and electron energy analyser - a ScientaOmicron HiPP-3 analyser (Cai et al., 2019) - remain in place, while the sample 
environments are exchanged. In addition, the endstation has a stationary UHV preparation chamber (base pressure $\left.1 \times 10^{-10} \mathrm{mbar}\right)$, load lock chamber $\left(1 \times 10^{-9} \mathrm{mbar}\right)$ with a sample carousel for six samples and with halogen lamps for quick bakeout, and radial distribution chamber (UFO, $1 \times 10^{-10} \mathrm{mbar}$ ) for transfer of samples between the different parts of the system and likewise equipped with a sample storage carousel for six samples. The average time for sample transfer between any two places is less than a minute. The endstation makes use of a gas system for up to eight gases. This gas system is described in more detail below.

The ScientaOmicron HiPP-3 electron energy analyser has a differential pumping stage and electrostatic lens system that allows for AP operation at up to $30 \mathrm{mbar}$ at $0.3 \mathrm{~mm}$ nozzle diameter. The analyser is placed horizontally, in the plane of the storage ring and at $55^{\circ}$ with respect to the direction of the $\mathrm{X}$-ray beam. The microchannel plate detector can be equipped with two different cameras with either $17 \mathrm{~Hz}$ or $120 \mathrm{~Hz}$ frame rate, which allows $c a 60 \mathrm{~ms}$ and $8 \mathrm{~ms}$ time resolution in fixed mode, respectively. A special property of the HiPP-3 electron analyser is that spatially resolved experiments along a line are possible by inserting an additional aperture in the nozzle. In our case the spatial resolution of the analyser was measured to be $8 \mu \mathrm{m}$ in the spatial detector direction.

An Al $K \alpha$ X-ray anode source together with monochromator is installed in the analysis chamber (ScientaOmicron MX650), which allows measurement with online synchrotron radiation light or offline anode X-ray source, and the endstation is also designed to allow measurement of XPS in both UHV and AP conditions. For AP measurements inside the docked cell a nozzle (in standard operation $0.3 \mathrm{~mm}$ diameter aperture for synchrotron light and $0.8 \mathrm{~mm}$ for $\mathrm{Al} \mathrm{K \alpha}$ $\mathrm{X}$-ray anode source operation) is placed on the analyser entrance. This nozzle is not a fixed part of the analyser, but is rather part of the cell, which implies that measurements outside the cell in UHV conditions are performed with a larger analyser opening. Another special feature of the HiPP-3 analyser is the swift acceleration mode (Edwards et al., 2015), which substantially improves its performance under ambient conditions, especially at low kinetic energies where electron scattering is most prominent. This mode is also the standard user mode, as it in general gives higher electron transmission than all other analyser modes.

The preparation chamber is a typical surface science preparation vacuum chamber equipped with low-energy electron diffraction (LEED, OCI BDL800IR-3G), quadrupole mass spectrometer (QMS, MKS Microvision 2, up to 200 a.m.u. [a.m.u. = atomic mass units]), quartz crystal microbalance (QCM, Prevac QO 40A1), ion source (Prevac IS $40 \mathrm{C} 1$ ), a range of ports for user equipment such as evaporators and a gas/vapour dosing system for four gases plus a noble gas for sample sputtering. The chamber manipulator is equipped with two slots for sample heating: an e-beam heater (up to $1200^{\circ} \mathrm{C}$ ) and a low degassing resistive heater (up to $600^{\circ} \mathrm{C}$ ). In the resistive heater slot, the sample can also be cooled to $-100^{\circ} \mathrm{C}$ using the vapour of liquid nitrogen. Pumping of the preparation chamber is achieved using a turbomolecular

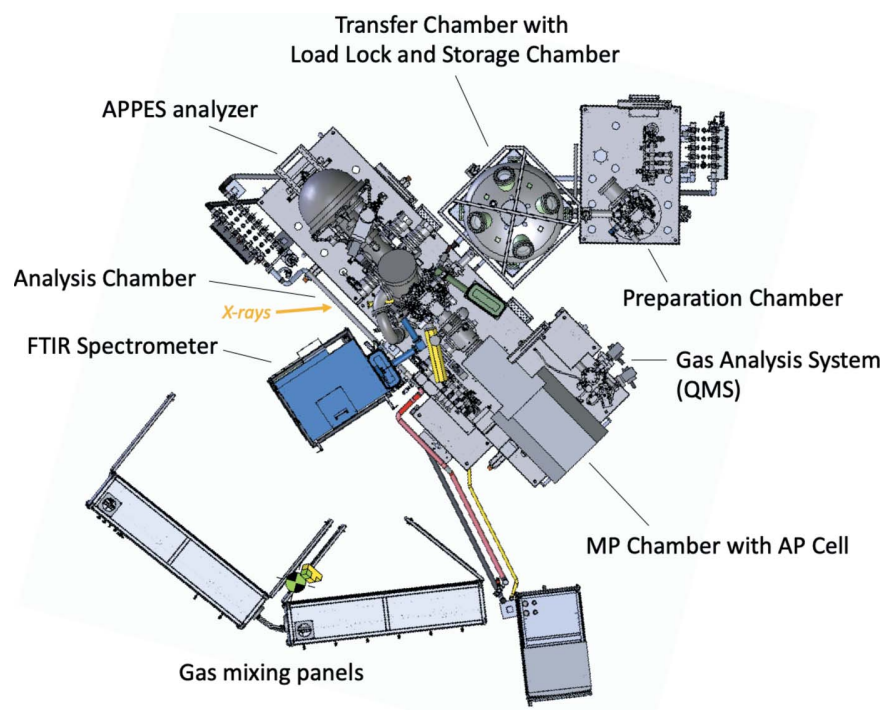

Figure 5

APXPS endstation at HIPPIE beamline with the catalysis AP setup.

(Pfeiffer HiPace 700) and an ion getter pump (Gamma Vacuum TiTan 400L).

The endstation standard setup shown in Fig. 5 is in the cellin-cell configuration. This configuration features, in addition to the above-mentioned vacuum vessels, an analysis chamber $\left(1 \times 10^{-10} \mathrm{mbar}\right)$, AP cell chamber (MP, $\left.1 \times 10^{-9} \mathrm{mbar}\right)$ and a quadrupole mass spectrometer (QMS, $1 \times 10^{-10} \mathrm{mbar}$ ) chamber. All chambers are separated from each other by gate valves. On the MP chamber a manipulator is mounted that carries the AP cell. The AP cell can be exchanged; presently, there exists one setup, the catalysis AP cell setup, which is described in more detail in Section 2.2.2.

The analysis chamber is a vacuum vessel of similar size to the preparation chamber. It features the same pumping scheme and a UHV manipulator with similar heating and cooling performance. It is connected to the endstation gas system (see below), and a Bruker Vertex 70v FTIR spectrometer can be attached to the analysis chamber for in situ XPS and IRRAS [IR reflection-absorption spectroscopy] measurement (see below). The MP chamber holds the AP cell. It can be valved off from the analysis chamber when doing UHV XPS measurements.

Samples are mounted on a flag-style sample holder with an on-board thermocouple connection with a design that makes it possible to image the samples both on Omicron and SPECS scanning tunnelling microscopes. Two choices of materials are available: Ta for experiments at high temperature in the absence of oxygen/water and stainless steel (304L, maximum $900^{\circ} \mathrm{C}$ ) for all other experiments. Sample holders may have a hole in the middle for direct sample heating with the laser (see below), thus ensuring that the sample body is the hottest place in an AP experiment.

The analysis and MP chambers and the AP cell manipulator are mounted on moveable rails. Using these rails, this setup can be removed (Fig. 6) and substituted by a vacuumchamber-based AP cell setup. At present, one such setup 


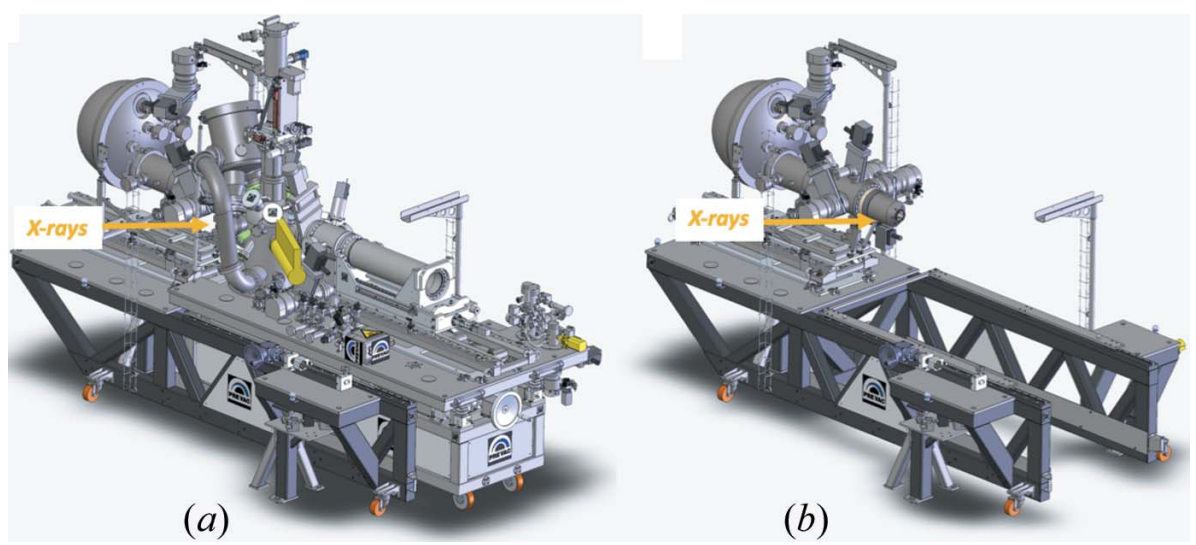

Figure 6

Exchanging AP cells at HIPPIE. (a) By the replacement of the existing AP cell. (b) By replacement of entire analysis and MP chambers.

exists: the electrochemical/liquid cell (EC), described in Section 2.2.3.

2.2.2. Catalysis AP cell. General description. A cell-in-cell approach already previously implemented at MAX IV is adopted for the catalysis AP cell (Schnadt et al., 2012; Knudsen et al., 2016). As described above, the cell is retractable. It is isolated in the MP chamber during UHV operation of the endstation and moved into the analysis chamber and docked to the electron energy analyser in AP operation. In docking mode, the analysis chamber maintains a pressure below $10^{-7}$ mbar when the AP cell itself is filled up to around 5 mbar. The X-ray beam from the undulator source or X-ray anode enters the AP cell through an X-ray window $(200 \mathrm{~nm}$ silicon nitride on silicon frame). The cell also has viewports for a camera view and a visible light source.

The sample normal is aligned to the symmetry axis of the analyser electrostatic lens system. The sample can be moved laterally, while sample rotation is not possible inside the cell. The sample is heated from the back by a fibre-coupled IR laser emitting $800 \mathrm{~nm}$ at a maximum power of $2.8 \mathrm{~W}$. Temperatures up to $600^{\circ} \mathrm{C}$ can be obtained in a gaseous atmosphere at a few mbars of pressure. Cooling to $-10^{\circ} \mathrm{C}$ is possible using ethanol as chilling agent. The laser heating stage can be replaced by a ceramic heater.

Gas delivery and gas analysis system. The gas inlet system of the catalysis AP cell contains eight gas lines equipped with individual mass flow controllers (MFCs) (Brooks GF125 with flows up to 30 s.c.c.m. [s.c.c.m. is standard cubic centimetres per minute]). The setup allows permanent installation of standard gases such as $\mathrm{H}_{2}, \mathrm{O}_{2}, \mathrm{CO}$ and $\mathrm{CO}_{2}$, as well as userdefined gases without frequent venting and time-consuming bakeout of the gas lines. The pre-defined gas mixture from the MFCs is dosed into the AP cell, either directly or via an adjustable leak valve. This dual type of inlet systems gives our users the possibility to dose gas mixtures at any total pressure between $1.0 \times 10^{-8}$ and 30 mbar.

The catalysis AP cell is equipped with two different pumping lines with a $4 \mathrm{~mm}$ inner diameter tube and three slots with opening $7 \mathrm{~mm} \times 100 \mathrm{~mm}$ and connected to a $35 \mathrm{~mm}$ tube, and equipped with individually butterfly valves (VAT series
615). In a typical experiment the $35 \mathrm{~mm}$ pumping line is normally fully closed (by an additional in-vacuum valve at the cell) and the $4 \mathrm{~mm}$ pumping line partly open. In order to reach 1 mbar under these conditions a total flow of $c a$ 3 s.c.c.m. is needed. Also, with these settings and a cell volume of 11 the gas exchange time becomes $6 \mathrm{~s}$. However, the adjustable pumping speed of the cell allows the user to change the gas exchange time for a given pressure. Faster gas exchange times are here achieved by increasing the flow and pumping speed.

The pressure inside the cell is measured by an in-vacuum Pirani gauge (Pfeiffer-vacuum TTR 91) for in situ pressure measurements between $1 \times 10^{-4}$ and 30 mbar backed up by a combination of a capacitance manometer (pressure range from $1.33 \times 10^{-2}$ to 133 mbar, Pfeiffer-vacuum CCR 362) and a full-range gauge (pressure range from $1 \times 10^{-9}$ to $1 \times 10^{3} \mathrm{mbar}$, Pfeiffervacuum PKR360) placed on the AP cell's pumping line.

The AP cell's inlet and outlet lines as well as the first differential pumping stage of the analyser are connected to a quadrupole mass spectrometer (Hiden HAL/3F PIC) via a combination of automatic angle and leak valves, providing a way for the quick analysis of the gas composition before or after its contact with the sample. The design avoids artificial pressure build-ups and dead volumes in the gas pipes. The users can change from probing the inlet to probing the outlet gas composition within $5 \mathrm{~s}$.

The fast switching between gas mixtures inside the cell was demonstrated in an experiment, in which the inlet composition oscillated in a fast and reproducible fashion as illustrated in Fig. 7. The left panel shows an image plot of $\mathrm{O} 1 \mathrm{~s}$ gas-phase spectrum recorded during a train of pulses of pure $\mathrm{CO}(5.5 \mathrm{~s}$ duration) alternating with the pulses of pure $\mathrm{O}_{2}$ (5.5 s duration). In total, ten such pulses were injected at 30 s.c.c.m. total flow and 1 mbar total pressure. Before and after the injection of the pulses a 1:1 CO: $\mathrm{O}_{2}$ composition was established at a flow rate of 15 s.c.c.m. at each mass flow controller. Gas injection started at time 0 . The right panel in Fig. 7 shows the integrated signal of the $\mathrm{CO}$ (red) and $\mathrm{O}_{2}$ (blue) components. Using the 1:1 CO: $\mathrm{O}_{2}$ composition set by the MFCs, the integrated signals were normalized to the same intensity at time 0 .

Fig. 7 illustrates that it takes $c a 50 \mathrm{~s}$ at a MFC gas-flow setting of 30 s.c.c.m. before the gas pulses arrive at the sample position. Smaller total flows will result in longer waiting times. Fig. 7 also demonstrates that it is possible to maintain the shape of the gas pulse train, which is made up from pulses with different composition, for at least the $50 \mathrm{~s}$ it takes to reach the sample position. This observation clearly demonstrates laminar flow within the inlet line of the HIPPIE gas system.

Polarization-modulated IR reflection-absorption spectroscopy setup. A Bruker Vertex 70v FTIR spectrometer with allin-vacuum beam path and polarization modulation (PM) 


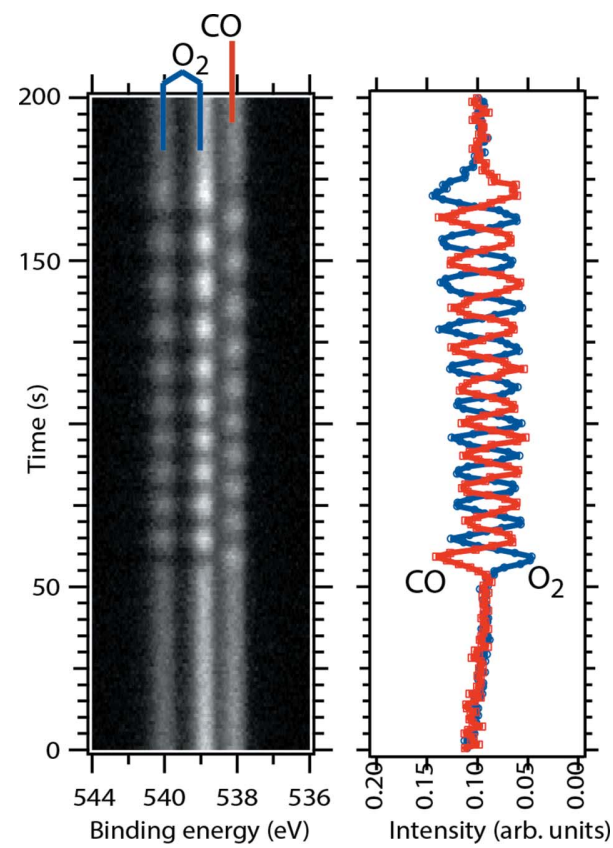

Figure 7

Left: $\mathrm{O} 1 s$ image plot measured with $\sim 7 \mathrm{~Hz}$ and a photon energy of $650 \mathrm{eV}$ and the sample slightly retracted such that no secondary electrons from the sample surface reach the electron analyser. Right: integrated $\mathrm{CO}$ and $\mathrm{O}_{2}$ signal obtained from the $\mathrm{O} 1 \mathrm{~s}$ image plot displayed as a function of time.

module can be attached to the catalysis AP cell setup (blue and green components in Fig. 5), allowing simultaneous IRRAS and XPS measurements under in situ conditions. The IR beam first passes a polarization modulator [ $42 \mathrm{kHz}$ PEM (AR-coated) and F350 polarizer]. Via a gold-covered plane mirror and a gold-covered out-off-axis parabolic (OAP) mirror the light is transferred into the catalysis AP cell via $\mathrm{ZnSe}$ viewports separating the beam path pipes, analysis chamber and catalysis AP cell, respectively. The beam illuminates the sample at $7^{\circ}$ grazing incidence. After reflection by the sample the light goes through the same series of IR lighttransmitting viewports. A single OAP mirror is used to reflect the light into the detection module with a MCT detector (medium band, spectral range $12000-600 \mathrm{~cm}^{-1}$ ). The combined wavenumber range of the system is 8000 to $720 \mathrm{~cm}^{-1}$ with a standard resolution of $0.4 \mathrm{~cm}^{-1}$. The simultaneous use of PM-IRRAS and APXPS is illustrated in Section 3.3.

2.2.3. Electrochemical/liquid cell. A dedicated cell built to use another switching approach is available for XPS measurements on liquids as well as liquid-gas and solid-liquid interfaces. The versatility of this chamber allows the design of experiments with non-standard sample environments, and it is therefore not limited only to liquid-gas and solid-liquid interfaces. This chamber is connected only to the ScientaOmicron electron energy analyser, but not the radial distribution chamber and other parts of the endstation. The main application of the chamber is operando measurements on electrochemical (EC) systems and hence it is denoted as the 'EC cell'.
The EC cell is a vacuum vessel with a background pressure of $1 \times 10^{-5}$ mbar. It has a large loadlock-style port (door) for quick access to the chamber's interior for sample loading. The chamber can be backfilled with gases and vapours at pressures up to $\sim 50$ mbar (when using a $0.3 \mathrm{~mm}$ front cone opening), and the gaseous atmosphere can be heated to $\sim 90^{\circ} \mathrm{C}$ by halogen lamps. A four-axis manipulator ( $X Y Z$ and rotation) can be inserted from the top, and a three-axis manipulator ( $X Y Z$ ) with cooling and heating functionality (via liquid coolant media) can be inserted from the bottom. Two top manipulators are available: one for liquid jet and one for electrochemistry experiments. A custom-designed glovebox can be attached to the EC cell and is equipped with a moisture detector (Mbraun, MB-MO_SE1) and an oxygen detector (Mbraun, MB-OX-SE1). The glovebox provides inert conditions for sample introduction and thus allows sensitive sample measurement at the endstation.

The liquid jet manipulator provides the possibility for APXPS measurements of surfaces of liquids as well as the liquid-gas interfaces. The setup (Microliquids) contains a glass nozzle with a 15 or $20 \mu \mathrm{m}$ opening, connected to a liquid supply pump (0.01-9.9 $\mathrm{ml} \mathrm{min}^{-1}$ liquid flow) to provide a pressurized liquid flow through the nozzle (Fig. 8, top left). As the liquid is ejected from the nozzle it forms a jet which remains undisrupted for a length dependent on the liquid pressure and the opening of the nozzle. Typically, the jet is intact up to a few $\mathrm{mm}$, after which it breaks down into droplets. A truncated conical copper trap (catcher) with an opening of $8 \mathrm{~mm}$ and a volume of $300 \mathrm{ml}$ is mounted on the bottom manipulator. It collects the ejected liquid. The temperature of the collected liquid can be controlled and defines the vapour pressure in the chamber.

The electrochemical top manipulator is equipped with three electrical feedthroughs, where EC electrodes can be mounted, while the bottom manipulator is equipped with two electrical feedthroughs and is designed to hold a container for liquid electrolytes. The system is designed to carry out 'dip-and-pull' (also known as 'meniscus' method) experiments, in which up to three electrodes can simultaneously be plunged into a liquid electrolyte and retracted to allow for the XPS investigation of the liquid-solid interface during electrochemical control of the sample (Fig. 8, top right).

For a test of the probing depth and the continuity of the potential profile across the thin liquid film, a Pt foil sample and $0.1 M \mathrm{KOH}$ solution were used. Fig. 8 shows Pt $4 f$ (bottom left) and $\mathrm{O} 1 s$ (bottom right) XP spectra recorded after the $\mathrm{Pt}$ sample was first immersed and then partially pulled out from the $\mathrm{KOH}$ solution. The thickness of the $\mathrm{KOH} /$ water film at the measurement point was estimated by the attenuation of the $\mathrm{Pt} 4 f$ signal using Lambert-Beer law for XPS: $I=I_{0} \exp \{-[\lambda /(d \sin \theta)]\}$ where $\lambda$ is electron IMFP in liquid water (Emfietzoglou \& Nikjoo, 2007), $d$ is layer thickness and $\theta$ is takeoff angle (Fadley, 2010). It was found to be $20 \mathrm{~nm}$. At this liquid film thickness, it took approximately $3 \mathrm{~min}$ to record a single Pt $4 f$ spectrum using electrons of kinetic energy $1726 \mathrm{eV}$ (1800 eV photon energy). Previously, the usage of 'tender' X-rays (3-6 keV) was considered necessary for 

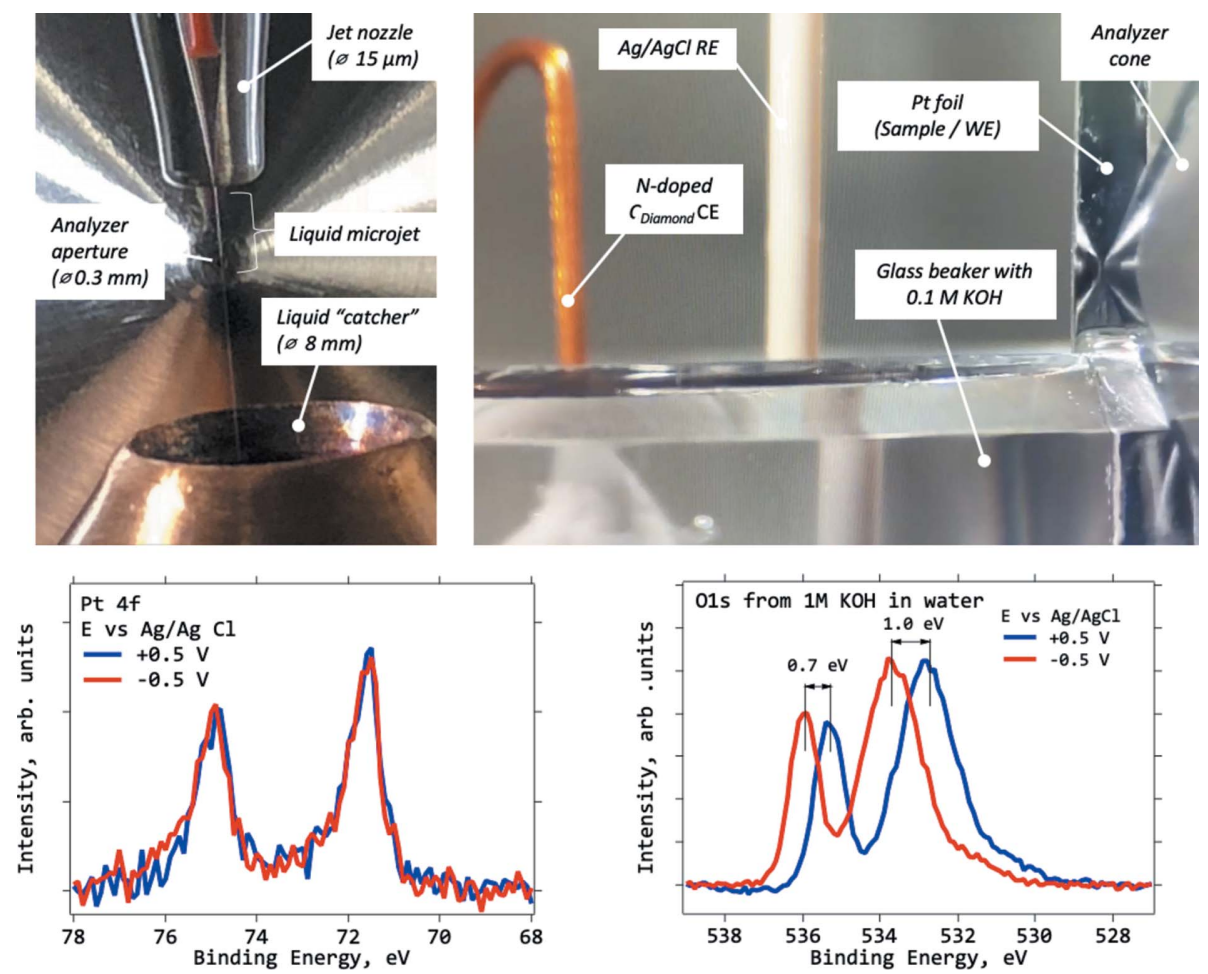

Figure 8

Electrochemical (EC) cell at HIPPIE beamline. Liquid microjet (top left) emerging from the end of a $20 \mu \mathrm{m}$ glass nozzle into an opening of a 'catcher'. In the foreground an analyser cone with $300 \mu \mathrm{m}$ opening can be seen. Dip-and-pull setup (top right) showing sample (working electrode), Ag/AgCl reference and N-doped diamond counter-electrodes from right to left. The sample is in XPS position with the mirror reflection of the analyser cone being visible on the sample's surface. Pt $4 f$ (bottom left) and $\mathrm{O} 1 s$ (bottom right) XP spectra measured in the setup shown in the top-right panel at 24 mbar of $\mathrm{H}_{2} \mathrm{O}$ and room temperature. Blue (red) curves correspond to $+0.5 \mathrm{~V}(-0.5 \mathrm{~V})$ applied potential. Thickness of KOH electrolyte layer estimated by the attenuation of Pt signal (vacuum spectrum is not shown) is $c a 20 \mathrm{~nm}$. Each spectrum took $c a 3$ min to record. $h v=1800 \mathrm{eV}$, photon energy $=100 \mathrm{eV}$, exit slit $100 \mu \mathrm{m}$. Potentials are with respect to $\mathrm{Ag} / \mathrm{AgCl}$ reference electrode.

probing the solid-liquid interfaces with XPS (Axnanda et al., 2015). To our knowledge, this is the first time that the dip-andpull method is demonstrated using soft X-rays. The O $1 s \mathrm{XP}$ spectrum demonstrates two features with the low-bindingenergy component corresponding to liquid water and the highbinding-energy one to gas-phase $\mathrm{H}_{2} \mathrm{O}$. Different potentials were applied to the sample with the blue (red) curves, representing spectra recorded at $+0.5 \mathrm{~V}(-0.5 \mathrm{~V})$. Due to the grounding of the sample the $\mathrm{Pt}$ spectra overlap. The $\mathrm{O} 1 \mathrm{~s}$ spectra, on the other hand, undergo a shift to lower binding energy when the potential is changed from a negative to a positive value: the liquid component shifts by $1.0 \mathrm{eV}$ and the gas-phase one by $0.7 \mathrm{eV}$. The equality of the shift of the liquid component and the difference in applied potentials imply that the potential is carried through the thin film without any losses. The drop occurs at the liquid-solid interface, which is normal behaviour for such systems (Shavorskiy et al., 2017).

\section{Scientific examples}

3.1. Following dynamic phase changes under a graphene cover

In this example, we will demonstrate how gas pulses, the intense light at the HIPPIE beamline and fast acquisition of APXPS spectra can be used to follow a simple surface reaction
- $\mathrm{H}_{2}$ oxidation - below graphene flakes on $\operatorname{Ir}(111)$. Fig. 9(a) shows image plots of the $\mathrm{O} 1 s$ and $\mathrm{C} 1 s$ core levels recorded in situ at $370 \mathrm{~K}$ and $1 \mathrm{mbar}$ with $1 \mathrm{~Hz}$ and $4.2 \mathrm{~Hz}$, respectively, on an $\operatorname{Ir}(111)$ surface half-covered by graphene flakes. While recording the XPS data the flakes were exposed to 10 s.c.c.m. $\mathrm{O}_{2}$ and two $50 \mathrm{~s}$ pulses of 9:1 $\mathrm{H}_{2}: \mathrm{O}_{2}$ s.c.c.m. marked in the figure.

Starting with the $\mathrm{O} 1 s$ data, oxygen on the surface is signalled by a main component near $530 \mathrm{eV}$ while the $\mathrm{O}_{2}$ in the gas phase is visible as a doublet component at 538.5 and $539.5 \mathrm{eV}$. The $\mathrm{O}$-surface component is assigned to a $p(2 \times 1)-\mathrm{O}$ phase both on the bare $\operatorname{Ir}(111)$ patches and under the graphene flakes in agreement with previous work (Grånäs $e t$ al., 2012; Larciprete et al., 2012). Even though a clear intensity reduction of the $\mathrm{O}_{2}$ gas-phase component is observed when the gas phase is diluted by the $\mathrm{H}_{2}$ pulse and a slight shift towards higher binding energies can be observed in the timeresolved data, it is difficult to say much about the $\mathrm{H}_{2}$ oxidation below the graphene flakes. One of the reasons is because the O $1 s$ core level is weak and suffers from large background signal, and the other reason is because it is impossible to disentangle the oxidation on the bare $\operatorname{Ir}(111)$ patches and the oxidation below the graphene flakes. In contrast, the intense and sharp graphene component is very sensitive to the intercalated molecules or atoms below the flakes and a time evolution is clearly visible in the $\mathrm{C} 1 s$ image plot. Between the 

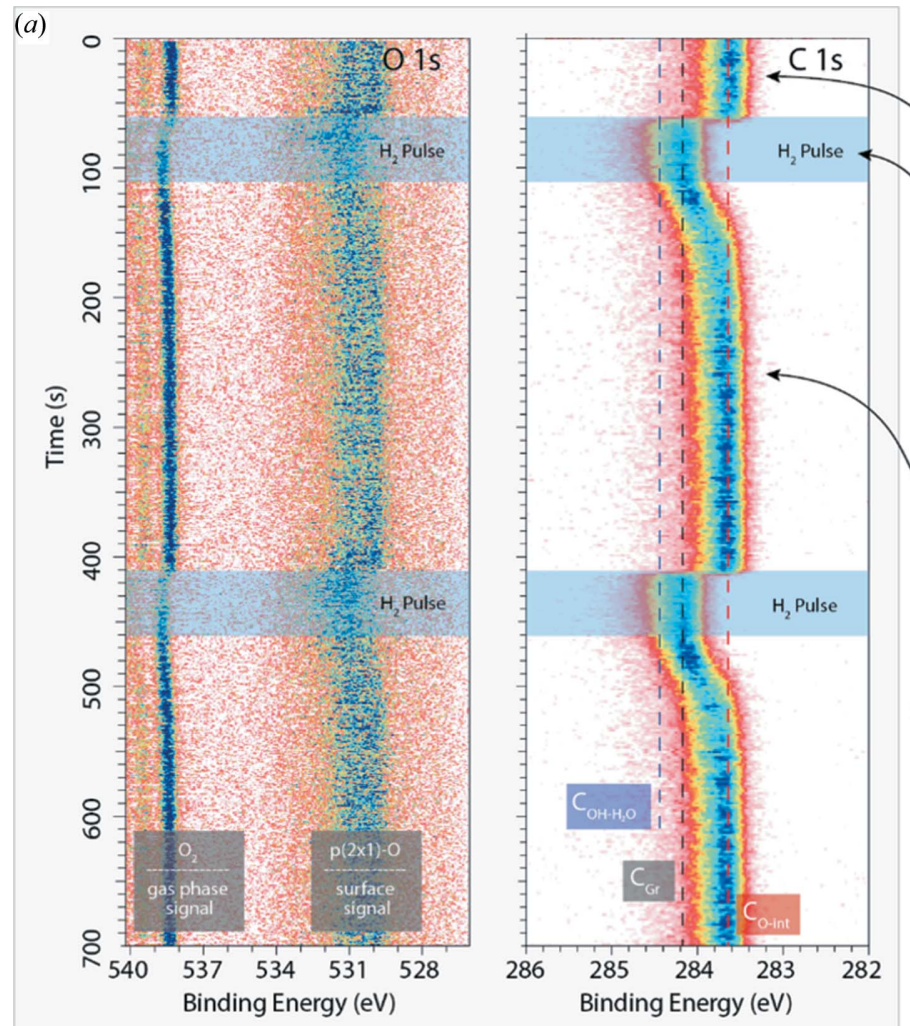

(b)

\section{$r(15$}
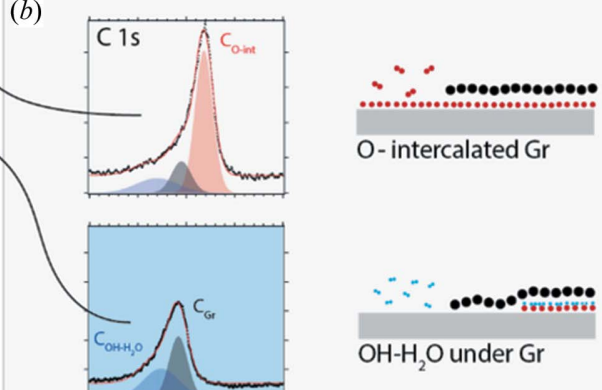

$\mathrm{OH}-\mathrm{H}_{2} \mathrm{O}$ under $\mathrm{Gr}$
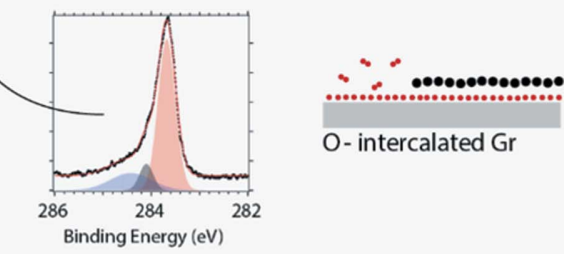

(a) Image plots of $\mathrm{O} 1 s$ and $\mathrm{C} 1 s$ spectra acquired with photon energies of $740 \mathrm{eV}$ and $390 \mathrm{eV}$, respectively, and after background removal. (b) Examples of curve fits done after averaging 50-100 individual spectra and sketches explaining how graphene is intercalated (see the text for the details of the different components). (c) Time evolution of different components obtained after binning the data eight times (points). The solid lines are averages of 20 points.

$\mathrm{H}_{2}$ pulses - in the pure $\mathrm{O}_{2}$ flow - the curve fitting shown in panel $(b)$ reveals that the $\mathrm{C} 1 s$ spectrum is dominated by the component at $283.73 \mathrm{eV}$ ( $\mathrm{C}_{\mathrm{O} \text {-int }}$ red component) matching well with graphene flakes intercalated by a $p(2 \times 1)-\mathrm{O}$ phase (Grånäs et al., 2012). In contrast, this component is fully absent in the centre of the $\mathrm{H}_{2}$ pulse. Instead, the curve fitting shows that the component is dominated by a component located at $284.15 \mathrm{eV}\left(\mathrm{C}_{\mathrm{Gr}}\right)$ and a broader component at $284.4 \mathrm{eV}$ $\left(\mathrm{C}_{\mathrm{OH}-\mathrm{H} 2 \mathrm{O}}\right)$. The black component is assigned to non-intercalated graphene (Grånäs et al., 2012), while the broad blue component is assigned to a mixed $\mathrm{OH}-\mathrm{H}_{2} \mathrm{O}$ phase formed and partly trapped below the graphene flakes (Grånäs, 2014). Altogether, these results are clear evidence for $\mathrm{H}_{2}$ oxidation occurring below the graphene flakes, thereby titrating away the intercalated $\mathrm{O}$ atoms. As the mixed $\mathrm{OH}-\mathrm{H}_{2} \mathrm{O}$ phase is denser than the $p(2 \times 1)-\mathrm{O}$ phase (Grånäs, 2014) part of each graphene flake will re-laminate to the underlying $\operatorname{Ir}(111)$ surface as a result of the conversion of $\mathrm{O}$ atoms to $\mathrm{OH}$ and $\mathrm{H}_{2} \mathrm{O}$ molecules. In essence, this is an effect of the attractive hydrogen bonds formed in the mixed $\mathrm{OH}-\mathrm{H}_{2} \mathrm{O}$ phase.

In Fig. $9(c)$ we plot the time evolution of the intensity of the different components. The semi-transparent data points were recorded with $4.2 \mathrm{~Hz}$ and binned eight times, while the solid lines are averaged over 20 data points. Interestingly, the oxidation proceeds very fast and within $7 \mathrm{~s}$ all $\mathrm{O}$ atoms below the graphene flakes are converted to $\mathrm{OH}$ or $\mathrm{H}_{2} \mathrm{O}$ molecules. In contrast, the re-intercalation by $\mathrm{O}_{2}$ is a slow process with a time constant, $\tau$, of $\sim 25 \mathrm{~s}$ [obtained from fitting to $1-A \exp (t / \tau)$ and denoting the time it takes to reach $63 \%$ of the saturation of the $\mathrm{C}_{\mathrm{O} \text {-int }}$ component].

To conclude, this suggests a picture in which the small hydrogen molecules diffuse fast under the graphene flakes, react with $\mathrm{O}$ atoms and form $\mathrm{OH}$ and $\mathrm{H}_{2} \mathrm{O}$ molecules. In contrast, the subsequent removal of mixed $\mathrm{OH}-\mathrm{H}_{2} \mathrm{O}$ phase and $\mathrm{O}$ intercalation proceed much slower with longer timescales. The example presented here demonstrates how the sharp and intense C $1 s$ peak of graphene can be used as an additional signal to study heterogeneous chemistry with a time resolution of seconds and sub-seconds. Further, the example illustrates how transient gas supply together with a bright light source and an efficient electron analyser can be used to get insights into how quickly phase changes occur on surfaces and how this affects their catalytic properties - a theme we currently push at the HIPPIE beamline.

\subsection{Electrochemistry}

The electrochemistry setup is demonstrated using a threeelectrode Li-ion battery (LIB) setup where the material of the working electrode (WE) and the electrolyte are monitored during the first charge and discharge. The LIB comprised a sputter-deposited thin film of $\mathrm{LiCoO}_{2}$ (used as a WE), a composite $\mathrm{Li}_{4} \mathrm{Ti}_{5} \mathrm{O}_{12}$ counter-electrode and a Li-metal reference electrode (RE). The electrodes were immersed in an 

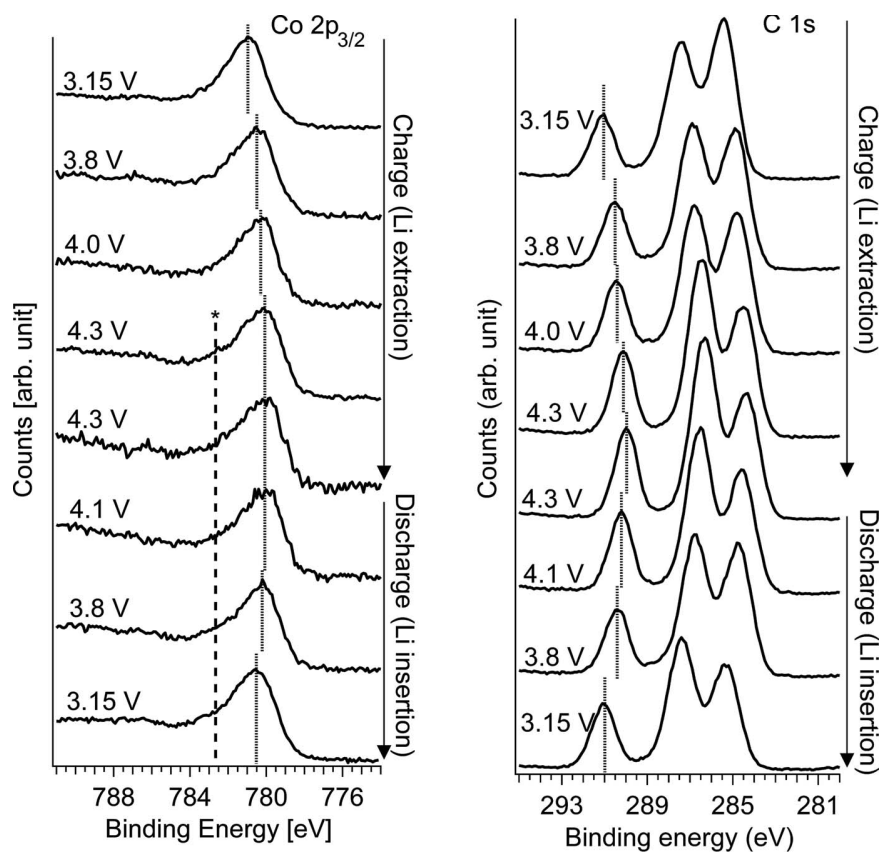

Figure 10

Left: Co $2 p_{3 / 2}$ during the charge and discharge. The asterisk indicates where peak broadening is present. Right: C $1 s$ spectra during the first charge and discharge. Dotted line indicates the peak of the carbonate group in the electrolyte solvent.

electrolyte with $1 \mathrm{M} \mathrm{LiClO}_{4}$ in propylene carbonate and by using the dip-and-pull approach a thin meniscus was formed whereas both the $\mathrm{LiCoO}_{2}$ material and the electrolyte could be monitored simultaneously. A potentiostat (Biologic SP150) was then used to charge and discharge the LIB in the measurement position using fixed potential steps during which APXPS measurements were conducted (using a photon energy of $1800 \mathrm{eV}$ ). After each potential change the current was allowed to stabilize below $0.1 \mu \mathrm{A}$ from the spike value of several $\mu \mathrm{A}$ before starting XPS measurements $(\sim 1.5 \mathrm{~h})$.

In Fig. 10 (left) the Co $2 p_{3 / 2}$ photoemission line is presented and the peak position is shifted to higher kinetic energies by about $1 \mathrm{eV}$ during charge and shifted back to lower kinetic energies during discharge (by approximately $0.5 \mathrm{eV}$ ). Also, a small broadening [indicated by the dashed line (*) in Fig. 10 (left)] emerges during the first charge and then remains throughout the discharge. The $\mathrm{C} 1 s$ spectra in Fig. 10 (right) represent the electrolyte at the interface with three peaks corresponding to three different carbon environments in the propylene carbonate molecule. The peak position of the carbonate peak [indicated by the dotted lines in Fig. 10 (right)] in each spectrum is presented in Fig. 11 as a function of WE potential versus $\mathrm{Li}^{+} / \mathrm{Li}$ (the $\mathrm{RE}$ ). The carbonate peak position shifts approximately $0.8-0.9 \mathrm{eV}$ per applied volt and there is an offset between charge and discharge of about $0.1 \mathrm{eV}$.

During charge (Li extraction) of $\mathrm{LiCoO}_{2}$ both cobalt and oxygen have been shown to partially oxidize (Kellerman et al., 2006), and in the Co $2 p$ photoemission spectra this results in a minor peak shift together with a broadening of the main peak and also an increase in the satellite (at about $8 \mathrm{eV}$ higher kinetic energy than the main peak) (Dahéron et al., 2008). The

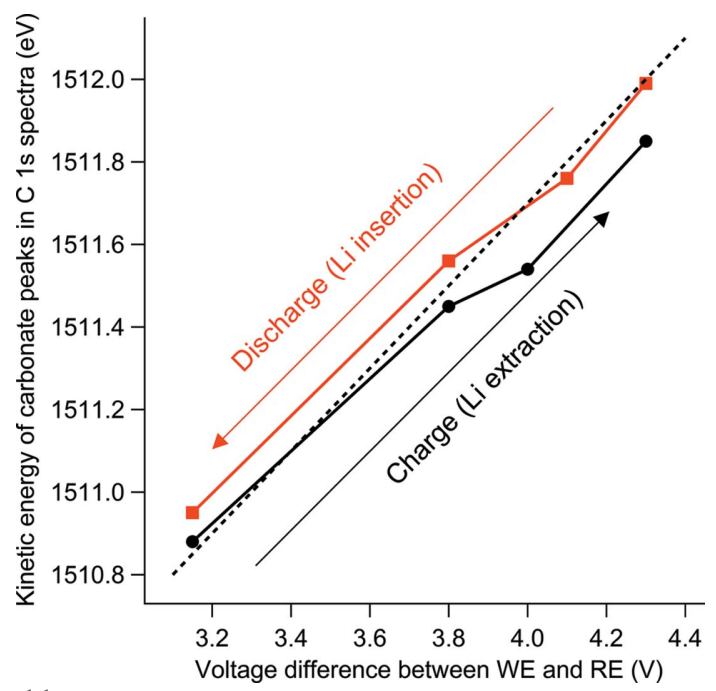

Figure 11

Peak position of the carbonate group in the electrolyte [deduced from Fig. 10 (right)] as a function of voltage difference between the working electrode (WE) and the reference electrode (RE). The dashed line represents the unity slope during the first charge and discharge of the battery.

results presented herein confirm the broadening of the main peak whereas the satellites in the presented samples have a different appearance [possibly due to a slightly different stoichiometry (Dupin et al., 2001)] and are less defined to allow for a detailed analysis. The shifting peak position of the Co $2 p_{3 / 2}$ in the presented operando APXPS series reveals that the active material of the WE is undergoing a change due to the $\mathrm{Li}$ extraction and insertion. This shift could be related to the change in electronic structure since, during $\mathrm{Li}$ extraction, $\mathrm{LiCoO}_{2}$ changes from a semiconductor to a more metallic state (Kellerman et al., 2006). During Li insertion (discharge) the peak position Co $2 p_{3 / 2}$ shifts back although not to its original position and the peak broadening remains, indicating that the material does not completely return to the pristine state. The electrolyte peak position shifts less than the ideal $1 \mathrm{eV}$ per $\mathrm{V}$ which suggests that a resistance is present in the cell, shifting the electrolyte potential less than the applied voltage difference. Also, the offset between charge and discharge indicates that the direction of the current possibly could affect interfacial mechanisms.

3.3. Adsorption of carbon monoxide on a Pt(111) surface at mbar pressures studied by PM-IRRAS and APXPS

The in situ XPS and PM-IRRAS results were collected using the PM-IRRAS setup described above, with a spectral resolution of $8 \mathrm{~cm}^{-1}$. The $\operatorname{Pt}(111)$ crystal was cleaned by a standard sputtering-annealing procedure. Following $\mathrm{CO}$ introduction into the analysis chamber the $\mathrm{O} 1 \mathrm{~s} \mathrm{XP}$ spectra [Fig. 12(a)] show $\mathrm{CO}$ adsorbed in the expected on-top $(532.7 \mathrm{eV})$ and bridge (531 eV) positions of $\mathrm{Pt}(111)$ (Knudsen et al., 2016; Björneholm et al., 1994). The on-top/bridge O 1 s peak intensity ratio was calculated after fitting all the XP spectra. The evolution of the ratio as a function of $\mathrm{CO}$ pressures is shown as an inset in Fig. 12(b) (black curve). As 


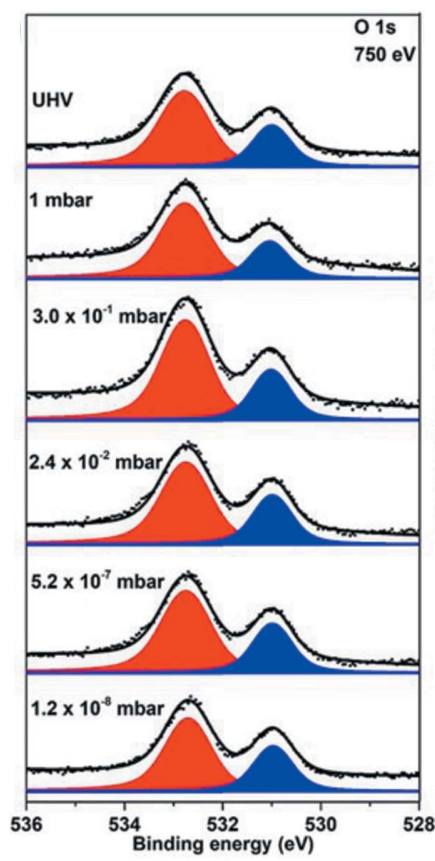

(a)

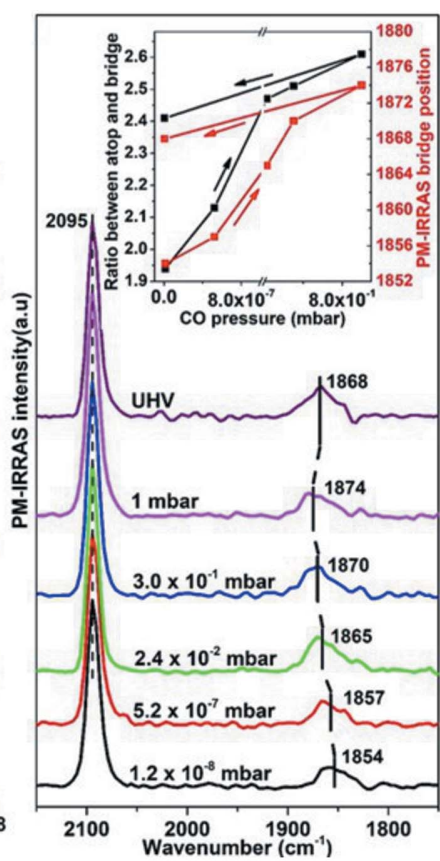

(b)
Figure 12

Simultaneous in situ (a) O 1 s XPS and (b) PM-IRRAS spectra from $\mathrm{Pt}(111)$ as a function of $\mathrm{CO}$ pressure. The $\mathrm{O} 1 s$ spectra were collected at $h v=750 \mathrm{eV}$. The inset in $(b)$ shows the correlation between the ratio of the $\mathrm{O} 1 s$ on-top and bridge peak areas (left axis).

expected, the on-top/bridge intensity ratio increases with $\mathrm{CO}$ pressure, which indicates that the surface accommodates an increasing coverage of on-top $\mathrm{CO}$ at higher $\mathrm{CO}$ pressures. Fig. 12(b) shows the simultaneously collected in situ PM-IRRAS spectra. The indicated peak positions reflect the centre of the integrated peak areas. Two absorption bands are observed at $2095 \mathrm{~cm}^{-1}$ and $1854 \mathrm{~cm}^{-1}$ at a CO partial pressure of $1.2 \times 10^{-8}$ mbar, consistent with CO adsorption on $\mathrm{Pt}(111)$ on-top and bridge sites, respectively (Carrasco et al., 2009, 2012). The position of the bridge component blue-shifts with increasing $\mathrm{CO}$ pressure. This blue shift has previously been interpreted as a signature for the formation of a compressed high-coverage $c(4 \times 2)$ CO layer on the surface and is interpreted as a result of an increased adsorbate-adsorbate repulsion (Carrasco et al., 2009). The formation of the highcoverage $\mathrm{CO}$ phase changes the relative coverage of the $\mathrm{CO}$ adsorbed in on-top and bridge sites. In the inset of Fig. 12(b) this change in relative coverage is correlated with the IR position of the $\mathrm{CO}$ bridge band. At increasing bridge-to-ontop ratio, a blue shift in the $\mathrm{CO}$ bridge position is observed. Upon evacuation of the analysis cell, the $\mathrm{CO}$ on-top-to-bridge $\mathrm{O} 1 s$ intensity ratio decreases slightly due to $\mathrm{CO}$ desorption from the surface. The decrease in $\mathrm{CO}$ bridge surface coverage is immediately observed in PM-IRRAS as a red shift in the $\mathrm{CO}$ bridge position.

\section{Conclusion}

The HIPPIE beamline at the $3 \mathrm{GeV}$ ring of Sweden's national synchrotron radiation facility MAX IV Laboratory is a unique experimental system which allows users to employ the powerful APXPS technique for a wide range of scientific problems in various fields. Its high photon flux over a wide range of photon energies $(250-2200 \mathrm{eV})$ at high resolving power (more than 10000 and up to a maximum 32000) allows quick XPS and NEXAFS (near-edge X-ray absorption fine structure) measurements at pressures of up to $30 \mathrm{mbar}$. A variety of exchangeable cells enables the use of different complex environments; this would not be possible in a single/ fixed setup. A fully automated gas delivery and analysis system in combination with a fast detector allows studies of the kinetics of catalytic and other surface reactions with ms time resolution; the high flux at energies above $1500 \mathrm{eV}$ and up to the $\mathrm{P} K$ edge and the availability of the EC cell allow studies of the solid-liquid interface under full electrochemical control; finally, a liquid microjet insert makes it possible to study surfaces of liquids and their interface with gas using a single instrument.

\section{Acknowledgements}

We gratefully acknowledge all of our colleagues at the MAX IV Laboratory who took part in the design, installation, alignment and measurement of the HIPPIE project (in alphabetical order): Marcus Agåker, Margit Andersson, Jesper N. Andersen, Antonio Bartalesi, Michael Gilg, Franz Hennies, Brian N. Jensen, Mathieu Leme, Mirjam Lindberg, Jörgen Lundh, Nahed Manjed, Mikko-Heikki Mikkelä, Alexei Preobrajenski, Peter Sjöblom, Conny Såthe, Samuli Urpelainen, Maxim Tchaplyguine, Erik Wallén. We also acknowledge Frank Siewert from Helmholtz Zentrum Berlin for optics metrology measurements. We are grateful for the fruitful discussions with the suppliers of the main components, FMB Berlin (mirror chambers), Toyama (PGM chamber and exit slit), Prevac (endstation vacuum system) and ScientaOmicron (endstation electron analyser).

\section{Funding information}

The MAX IV Laboratory is financed by the Swedish Research Council, the HIPPIE beamline was financed by Knut and Alice Wallenberg and Swedish Universities. We also acknowledge the Swedish Research Council (Vetenskapsrådet) for funding (grant Nos. 2004-4404, 2010-5080, 201703871 and 2017-04840).

\section{References}

Agåker, M., Mueller, F., Norsk Jensen, B., Åhnberg, K., Sjöblom, P., Deiwiks, J., Henniger, H., Pärna, R., Knudsen, J., Thiagarajan, B. \& Såthe, C. (2020). J. Synchrotron Rad. 27, 262-271.

Arble, C., Jia, M. \& Newberg, J. T. (2018). Surf. Sci. Rep. 73, 3757.

Axnanda, S., Crumlin, E. J., Mao, B., Rani, S., Chang, R., Karlsson, P. G., Edwards, M. O. M., Lundqvist, M., Moberg, R., Ross, P., Hussain, Z. \& Liu, Z. (2015). Sci. Rep. 5, 9788.

Baumgärtel, P., Witt, M., Baensch, J., Fabarius, M., Erko, A., Schäfers, F. \& Schirmacher, H. (2016). AIP Conf. Proc. 1741, 040016. 
Björneholm, O., Nilsson, A., Tillborg, H., Bennich, P., Sandell, A., Hernnäs, B., Puglia, C. \& Mårtensson, N. (1994). Surf. Sci. 315, L983-L989.

Boronin, A. I., Bukhityarov, V. I., Vishnevskii, A. L., Boreskov, G. K. \& Savchenko, V. I. (1988). Surf. Sci. 201, 195-210.

Cai, Q., Dong, Y., Han, Y., Mao, H., Zhang, H., Karlsson, J., Åhlund, J., Tai, Y., Yu, Y. \& Liu, Z. (2019). Nucl. Sci. Technol. 30, 81.

Carrasco, J., Hodgson, A. \& Michaelides, A. (2012). Nat. Mater. 11, 667-674.

Carrasco, J., Michaelides, A., Forster, M., Haq, S., Raval, R. \& Hodgson, A. (2009). Nat. Mater. 8, 427-431.

Dahéron, L., Dedryvère, R., Martinez, H., Ménétrier, M., Denage, C., Delmas, C. \& Gonbeau, D. (2008). Chem. Mater. 20, 583-590.

Dupin, J. C., Gonbeau, D., Benqlilou-Moudden, H., Vinatier, Ph. \& Levasseur, A. (2001). Thin Solid Films, 384, 23-32.

Edwards, M. O. M., Karlsson, P. G., Eriksson, S. K., Hahlin, M., Siegbahn, H., Rensmo, H., Kahk, J. M., Villar-Garcia, I. J., Payne, D. J. \& Åhlund, J. (2015). Nucl. Instrum. Methods Phys. Res. A, 785, 191-196.

Emfietzoglou, D. \& Nikjoo, H. (2007). Radiat. Res. 167, 110-120.

Fadley, C. S. (2010). J. Electron Spectrosc. Relat. Phenom. 178-179, $2-32$.

Feifel, R., Baev, A., Gel'mukhanov, F., Ågren, H., Andersson, M., Öhrwall, G., Piancastelli, M. N., Miron, C., Sorensen, S. L., Naves de Brito, A., Björneholm, O., Karlsson, L. \& Svensson, S. (2004). J. Electron Spectrosc. Relat. Phenom. 134, 49-65.

Follath, R., Senf, F. \& Gudat, W. (1998). J. Synchrotron Rad. 5, 769 771.

Grånäs, E. (2014). Above and Below Graphene: Nanoparticle Chemistry and Interface Reactions. Lund University.

Grånäs, E., Knudsen, J., Schröder, U. A., Gerber, T., Busse, C., Arman, M. A., Schulte, K., Andersen, J. N. \& Michely, T. (2012). ACS Nano, 6, 9951-9963.

Grass, M. E., Karlsson, P. G., Aksoy, F., Lundqvist, M., Wannberg, B., Mun, B. S., Hussain, Z. \& Liu, Z. (2010). Rev. Sci. Instrum. 81, 053106.

Held, G., Venturini, F., Grinter, D. C., Ferrer, P., Arrigo, R., Deacon, L., Quevedo Garzon, W., Roy, K., Large, A., Stephens, C., Watts, A., Larkin, P., Hand, M., Wang, H., Pratt, L., Mudd, J. J., Richardson, T., Patel, S., Hillman, M. \& Scott, S. (2020). J. Synchrotron Rad. 27, 1153-1166.

Joyner, R. W. \& Roberts, M. W. (1979). Chem. Phys. Lett. 60, 459-462. Joyner, W., Roberts, M. W. \& Yates, K. (1979). Surf. Sci. 87, 501-509.

Kato, M., Morishita, Y., Oura, M., Yamaoka, H., Tamenori, Y., Okada, K., Matsudo, T., Gejo, T., Suzuki, I. \& Saito, N. (2007a). J. Electron Spectrosc. Relat. Phenom. 160, 39-48.
Kato, M., Morishita, Y., Oura, M., Yamaoka, H., Tamenori, Y., Okada, K., Matsudo, T., Gejo, T., Suzuki, I. H. \& Saito, N. (2007b). AIP Conf. Proc. 879, 1121-1124.

Kellerman, D. G., Galakhov, V. R., Semenova, A. S., Blinovskov, Ya. N. \& Leonidova, O. N. (2006). Phys. Solid State, 48, 548-556.

Kirkpatrick, P. \& Baez, A. V. (1948). J. Opt. Soc. Am. 38, 766.

Knudsen, J., Andersen, J. N. \& Schnadt, J. (2016). Surf. Sci. 646, 160169.

Kokkonen, E., Lopes da Silva, F., Mikkelã, M.-H., Johansson, N., Huang, S.-W., Lee, J.-M., Andersson, M., Bartalesi, A., Reinecke, B. N., Handrup, K., Tarawneh, H., Sankari, R., Knudsen, J., Schnadt, J., Såthe, C. \& Urpelainen, S. (2021). J. Synchrotron Rad. 28, 588-601.

Larciprete, R., Ulstrup, S., Lacovig, P., Dalmiglio, M., Bianchi, M., Mazzola, F., Hornekaer, L., Orlando, F., Baraldi, A., Hofmann, P. \& Lizzit, S. (2012). ACS Nano, 6, 9551-9558.

Sasaki, S., Kakuno, K., Takada, T., Shimada, T., Yanagida, K. \& Miyahara, Y. (1993). Nucl. Instrum. Methods Phys. Res. A, 331, 763-767.

Schnadt, J., Knudsen, J., Andersen, J. N., Siegbahn, H., Pietzsch, A., Hennies, F., Johansson, N., Mårtensson, N., Öhrwall, G., Bahr, S., Mähl, S. \& Schaff, O. (2012). J. Synchrotron Rad. 19, 701-704.

Schnadt, J., Knudsen, J. \& Johansson, N. (2020). J. Phys. Condens. Matter, 32, 413003.

Shavorskiy, A., Ye, X., Karslıoğlu, O., Poletayev, A. D., Hartl, M., Zegkinoglou, I., Trotochaud, L., Nemšák, S., Schneider, C. M., Crumlin, E. J., Axnanda, S., Liu, Z., Ross, P. N., Chueh, W. \& Bluhm, H. (2017). J. Phys. Chem. Lett. 8, 5579-5586.

Siegbahn, H. \& Siegbahn, K. (1973). J. Electron Spectrosc. Relat. Phenom. 2, 319-325.

Starr, D. E., Liu, Z., Hävecker, M., Knop-Gericke, A. \& Bluhm, H. (2013). Chem. Soc. Rev. 42, 5833-5857.

Urpelainen, S., Såthe, C., Grizolli, W., Agåker, M., Head, A. R., Andersson, M., Huang, S.-W., Jensen, B. N., Wallén, E., Tarawneh, H., Sankari, R., Nyholm, R., Lindberg, M., Sjöblom, P., Johansson, N., Reinecke, B. N., Arman, M. A., Merte, L. R., Knudsen, J., Schnadt, J., Andersen, J. N. \& Hennies, F. (2017). J. Synchrotron Rad. 24, 344-353.

Velasco-Vélez, J. J., Pfeifer, V., Hävecker, M., Wang, R., Centeno, A., Zurutuza, A., Algara-Siller, G., Stotz, E., Skorupska, K., Teschner, D., Kube, P., Braeuninger-Weimer, P., Hofmann, S., Schlögl, R. \& Knop-Gericke, A. (2016). Rev. Sci. Instrum. 87, 053121.

Wallén, E., Blomqvist, I., Bahrdt, J. \& Boergermann, F.-J. (2014). Proceedings of the 5th International Particle Accelerator Conference (IPAC2014), 15-20 June 2014, Dresden, Germany, pp. 1286-1288. TUPRO103. 